\title{
Olympics - The Road to Success
}

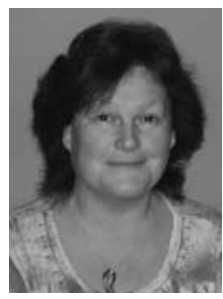

\section{Manda Dunne}

$\mathrm{O}$ lympic fever has really hit home and everyone is in the winning spirit! It's been great to see our medals gradually accumulating and even more interesting realising that it makes a difference to your day.

We feel proud of the team's achievement and discover that there is a particular sport that means more to us than it used to, or we discover a new sport that has never been of interest before, and you are now actively seeking more excitement and knowledge about that particular sport.

You can experience this feeling by attending the BARNA (British Anaesthetic and Recovery Nurses Association) conference! I feel very proud about the work we are putting into BARNA in conjunction with Kenes, and I hope that you have all had the chance to visit www.barna2012.com and to book your place at the forthcoming conference on Saturday, November 10th, at the Royal College of surgeons in London.

It feels as if we are like the Olympic athletes, in training for a new experience.

Our association re-launch is happening this November and we hope to take BARNA to a new and different level, in what we can offer you as our members and in how we can represent anaesthetic and recovery nursing as the very unique speciality that it is.
If you have never been to a BARNA conference before, or you have and are recommending it to your colleagues or indeed joining us again, please come and seek some of the excitement we can offer, and discover more in-depth and interesting knowledge of your speciality.

Our ultimate Gold Medal as BARNA is to be able to provide a high standard of education in anaesthetics and recovery and to represent every member in a professional capacity, enabling you to network with colleagues from around the world and to enhance your clinical experience.

In the spirit of the Olympics I would like to share this quote with you from Jesse Owens. He fought against all the odds to become the great athlete he was, going on to win four gold medals in the 1936 Olympics in Berlin. He once said:

'We all have dreams, but in order to make dreams come into reality, it takes an awful lot of determination, dedication, self-discipline, and effort'.

To enable our dreams for BARNA to transpire into success, this demands all of the above from your committee, so please come and support us as we look forward to welcoming you on Saturday, November 10th 2012 in London. You will have a great day! 